\title{
Evaluation of Indoor Environmental Radiation Level and Radiation Dose in Student Dormitory
}

\author{
Yu Liu, Xu Zhao, Junxin Zhang \\ Chengdu University of Technology, Chengdu, China \\ Email: zhangjunxin_1314@163.com
}

How to cite this paper: Liu, Y., Zhao, X. and Zhang, J.X. (2020) Evaluation of Indoor Environmental Radiation Level and Radiation Dose in Student Dormitory. Open Access Library Journal, 7: e6673.

https://doi.org/10.4236/oalib.1106673

Received: July 28, 2020

Accepted: August 22, 2020

Published: August 25, 2020

Copyright $\odot 2020$ by author(s) and Open Access Library Inc.

This work is licensed under the Creative Commons Attribution International License (CC BY 4.0).

http://creativecommons.org/licenses/by/4.0/ (c) (i) Open Access

\begin{abstract}
A large number of studies have shown that indoor radiation can damage our digestive organs, reproductive system, hematopoietic system and nervous system. In this topic, aiming to master the indoor environmental radioactivity level and the levels of radiation, the feasibility experiment plans with both appropriate measuring method and measuring instrument are designed to measure $\gamma$-radiation dose rate and Radon concentration of student dorm actually. Meanwhile, the radiation dose of students can be estimated through monitoring data, and the results can be evaluated to judge the pros and cons of living conditions. Besides, the indoor radiation monitoring results with the theory were compared, so that students can understand the radioactivity and radiation hazards from the data.
\end{abstract}

\section{Subject Areas \\ Radiation Physics}

\section{Keywords}

Indoor Radioactivity, Radiation Dose, Gamma Radiation Dose Rate, Radon Concentration

\section{Introduction}

With the development of social and economic level, higher requirements on the quality of life are pursued, while a new type of domestic pollution called radioactive pollution followed. Radioactivity can always be ignored by general public for their little knowledge about it. However, it will seriously harm people's health if they are exposed to ultra-standard radiation for a long time and especially cause tumors and other diseases. In order to understand the source and hazard of indoor radioactivity, experts have done numerous investigation and research on 
indoor radioactivity.

The research of Yang Qinyuan et al. [1] shows that the building materials are the main factor leading to the exposure of Chinese residents to radiation, while Liu Chunyu et al. [2] found that main factors affecting radon concentration are not construction materials but seasonal changes and the cleanliness of the dormitory. Moreover, Li Jinzhu et al. [3] pointed out that the main cause of indoor radioactive hazards was unqualified indoor decoration materials and abundant radon gas would escape from the foundation. In addition, other studies have shown that the urban and rural environment, indoor and outdoor environment, and floor height can also affect radon concentration, and the radon concentration level and monitoring method also ought to be timely modified. Generally, research shows that one of the sources of indoor radioactivity is the radionuclide contained in building materials [1] [3] [4] [5] (cement, brick, heat insulation materials, etc.), decorative materials [2] [6]-[11] (paint, floor tiles, etc.), and decorative items [12] [13] [14] [15] (furniture, exhibits, etc.). The other is the release of natural radioactive material [16] [17] [18] [19] (radon gas) from rocks and soil under the basement. In addition, the changes in radon concentration caused by seasonal changes make sense [2].

The school provides accommodation for the students and makes sure that the students are healthy. Thus, the purpose of this experiment is to intuitively understand the radioactivity situation inside the dormitory of students, master the indoor radon concentration value and dose rate, and provide a theoretical basis for whether the dormitory is suitable for living.

\section{Technic Method}

Utilizing the principle of $\mathrm{X}-\gamma$ radiation instrument (Figure 1(a)) and radon detector (Figure 1(b)), the experimental feasibility scheme is designed.

1) Design measuring points in the basis of dormitory distribution;

2) Field measurements with radiation instruments;

3) Data processing and analysis;

4) Draw conclusions.

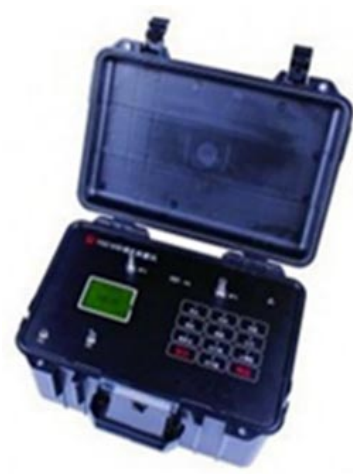

(a)

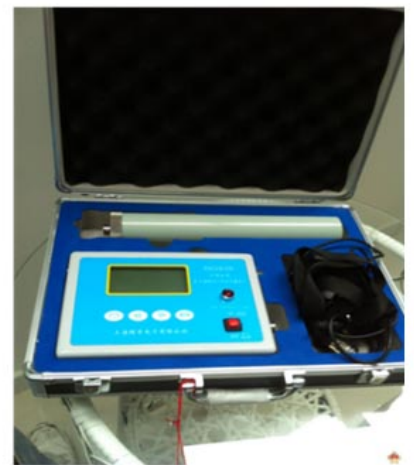

(b)

Figure 1. Radon detector (a) and X- $\gamma$ radiation instrument (b). 
According to the scheme, the data are monitored and radon concentration obtained by monitoring is compared with the radon concentration limit in indoor radon Concentration and Daughters Control Requirements (GB-T 16146-2015), and the results are evaluated.

The absorbed dose rate of each measuring point is converted into effective dose, after obtaining by $\mathrm{X}-\gamma$ radiometer, then efficient dose is compared with the limit in Basic Standard of Ionizing Radiation Protection and Radiation Source Safety (GB18871-2002), and the results are evaluated.

\section{Effective Dose Estimation Method}

1) Effective dose estimation method for internal exposure

According to Formula 1, the annual effective dose of indoor radon and its daughter can be calculated as radon and its daughter concentrations are measured.

$$
H=\operatorname{Cin} \times f i n \times t
$$

Cin: radon and its daughter concentration, $\mathrm{Bq} / \mathrm{m}^{3}$.

fin: Indoor dose conversion factor, $1.4108 \mathrm{~Sv}(\mathrm{Bqh} / \mathrm{ms})$.

t. Environmental stay time (residence factor).

2) Effective dose estimation method for external exposure

The absorbed dose rate is measured using the $\mathrm{X}$-dose rate meter. According to the Environmental Surface Dose Rate Measurement Specification (GB/T 14583-1993), the effective dose of radiation exposure to dormitory can be calculated by Formula 2,

$$
H=D r \times K \times t
$$

$H$ : Effective dose equivalent, Sv.

$D$ : Environmental radiation air absorption dose rate, $\mathrm{Gy} / \mathrm{H}$.

$K$ : Ratio of effective dose rate and air absorbed dose rate, $0.7 \mathrm{~Sv} / \mathrm{Gy}$.

$T$ : Residence time in the environment (residence factor 0.8 ).

\section{Monitoring of Radiation Levels}

\subsection{Dormitory Structure}

There are six residential buildings with the same size and pattern in students' dormitory. Each residential building is divided into area A (Figure 2, left) and area B (Figure 2, right), and six floors in total there. As shown in Figure 2, the dormitory pattern is the same for each floor, while the dormitory administrator and the study room are only arranged on the first floor.

\subsection{Indoor Radon Concentration Measurement}

\subsubsection{Principle of Measuring Radon Concentration}

For measuring indoor radon, the number of sampling points is determined by indoor area and site. Generally, 1 - 3 points for the room below $50 \mathrm{~m}^{2}, 3$ - 5 for $50-100 \mathrm{~m}^{2}$, and 5 at least for $100 \mathrm{~m}^{2}$ above, with diagonal or plum pattern layout point. 


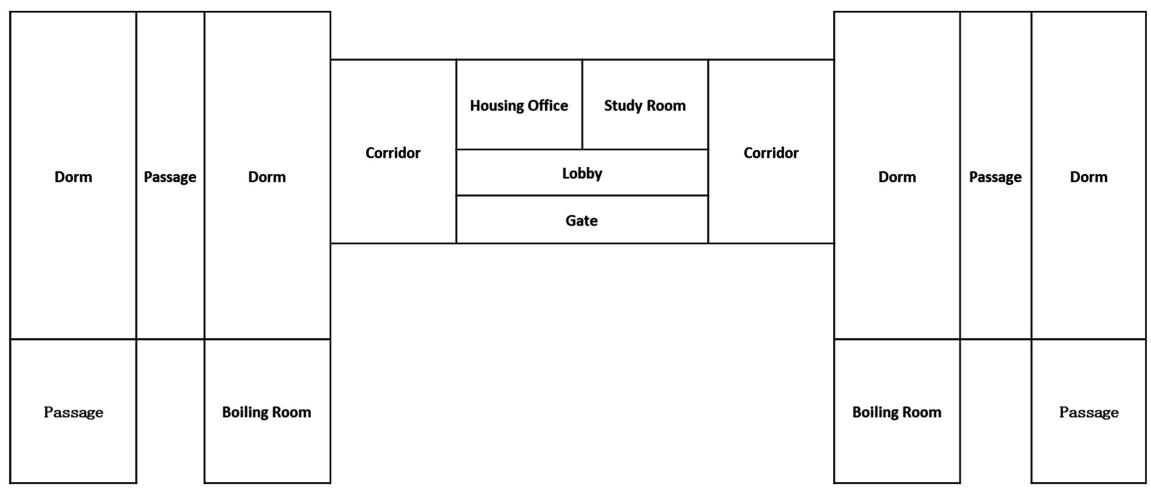

Figure 2. Schematic diagram of dormitory structure.

Diagonal layout point method is used for the dormitory measurement. The room of residential area is close to $50 \mathrm{~m}^{2}$, ignoring the middle part of each dormitory building, so one measuring point is set both area A and B of each floor. Totally, there are 12 measuring points in each building and 72 measuring points in the six residential buildings.

\subsubsection{Selection of Measuring Instruments}

In this measurement experiment, we need to measure the data at different locations, constantly move the instrument and get accurate data. According to the current conditions and actual measurement situation of our university, the FD216 environmental radon meter developed by Beijing Institute of Geology of Nuclear Industry is selected, because of its small in size, light in weight and easy to carry. Besides, it can be used for both AC and DC, USB data transfer can also be available.

\subsubsection{Introduction of the Instrument}

1) Instrument principle

D216 environment radon measurement instrument is mainly on the basis of scintillation method: the radon gas is pumped into the scintillation chamber, releasing $a$ particle, which makes $\mathrm{ZnS}$ (Ag) coating to glow, then the PMT transfers the light signal into electrical impulses. The control and measurement circuit, composed of single chip microcomputer, shapes the electric pulse output of the detector and carries out timing counting, thus radon concentration can be determined in the air (because the number of pulses per unit time is proportional to radon concentration). The principle block diagram is shown in Figure 3.

2) Basic operation

The instrument control panel is shown as follows,

In Figure 4, the function of FD216 environmental radon-measurement shows that it can measure radon in air, water and soil. The following is the basic operation of indoor air radon measurement,

a) Turn on the switch, set all basic parameters like time, date (button 9) etc.

(The switch should be turned on to preheat for more than 30 min before measuring.) 


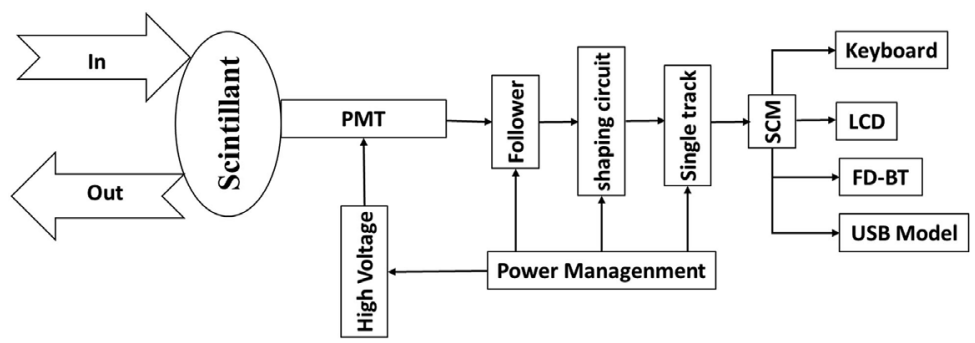

Figure 3. Schematic diagram of radon-measurement instrument.

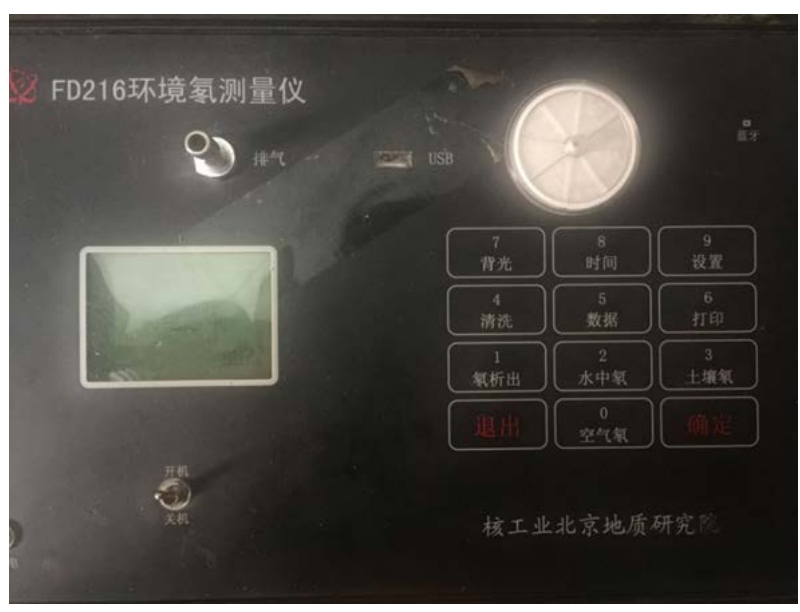

Figure 4. Control panel diagram.

b) Select air radon (button 0) to measure radon in indoor air.

c) Set the measurement parameters of air radon for the inflation time of 10 $\mathrm{min}$, the measurement time of $20 \mathrm{~min}$, and the exhaust time of $1 \mathrm{~min}$.

d) Fixed point measurement and record data at the end of each point measurement.

\subsubsection{The Process of Measuring Indoor Radon Concentration}

Radon concentration measurement in the dormitory will last for 6 days (from May 7, 2019 to May 13, 2019). The specific operation is as follows:

1) Calibrate the radon measurement instrument according to the standard before measurement;

2) The original value of the background is 0.02 , set to 0.37 according to the calibration certificate;

3) Check the spot and make measurement;

4) Collect the data after the measurement every day for six days.

\subsection{Measurement of Dose Rate of Radiation in Dormitory Room}

\subsubsection{Measurement Point Rules of Air Absorbed Dose Rate}

Due to the indoor location, the measurement instrument is required to monitor the data 1 meter above the ground, mainly measuring the absorbed dose rate of air generated by $\gamma$ radiation emitted by artificial and natural nuclides in the surrounding substances. The layout rules are determined by the purpose of mea- 
surement without any specific requirement. As shown in Figure 1, there are two rows of dormitories on one side of each floor total of 21 bedrooms, 12 on one side and 9 on the other. Select the side with 12 bedrooms and set up a measuring point per three dormitories apart, and three monitoring points in the middle of each building. There are 57 points in each dormitory and 342 points in the six residential buildings total.

\subsubsection{Selection of Measuring Instrument}

$\mathrm{BH} 3103 \mathrm{~B}$ portable $\mathrm{X}-\gamma$ dose rate instrument is selected for its high sensitivity, good energy response and angle response, and it can realize automatic measurement and operate and carry easily. The absorbed dose rate in the air can be measured and according to Formula 2, converted to obtain the dose received by students and make an evaluation.

\subsubsection{Introduction of the Instrument}

1) Instrument principle

When the X-ray hits the scintillator and generates light, a certain current signal can be formed by PMT, which will be transferred into a counting frequency through the I-F transformation. The stronger the radiation field, the greater the photocurrent per unit time, and the higher the counting frequency, which means that the dose rate of the radiation field in the air is proportional to the count rate measured. After the count signal is further processed by the electronic circuit, it is sent to the SCM processing system to realize the functions of data acquisition, display, storage and printing etc. The working principle block diagram is shown in Figure 5.

2) Basic operation

The control panel of the dose-rate meter is shown in Figure 6.

The basic operation of the instrument is as follows:

a) Connect instrument, the host and the probe;

b) Preheat the instrument for more than 1 minute after turning on;

c) Calibrate the instrument before operating;

d) Set the measurement time to be 3 minutes;

e) Press the button at the specified location to begin the measurement

f) Record the data after the measurement.

\subsubsection{The Process of Measuring the Absorbed Dose Rate of $\gamma$ Radiant} The absorbed dose rates of air in the dormitory were measured for 3 days (May 4 to June 6,2019$)$.

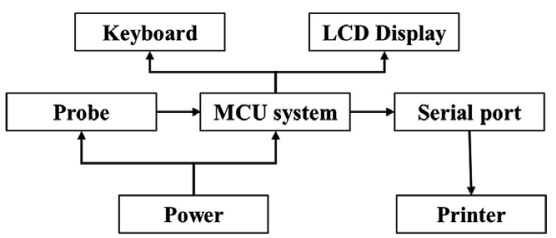

Figure 5. Measurement principle of dose-rate meter. 


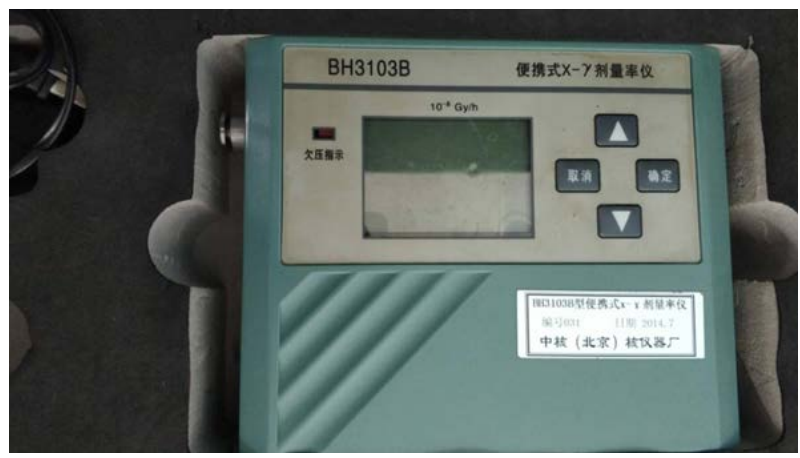

Figure 6. Control panel of dose-rate meter.

Calibrate the instrument before data measurement, and the measurement time of each building is nearly 4 hours.

\section{Results and Analysis}

\subsection{Concentration Level and Analysis of Radon}

Among all the measured data in the students' dormitory, the minimum value is 11.3 and the maximum value is 31.4. The difference between the two values is 20.1. With the Formula 3, formula for calculating standard deviation (SD), SD of radon gas per building can be got.

$$
\mathrm{SD}=\sqrt{\frac{1}{N-1} \sum_{i=1}^{N}\left(x_{i}-\bar{x}\right)^{2}}
$$

As shown in Table 3, 6 buildings and each building is 12 points, total 72 measuring points.

In Table 1, the average radon concentration in the dormitory on the No.2 building is the lowest, and that on the No.5 building is the highest. There is no regular radon concentration in the measured data. While the building materials of the six buildings are all arranged in the same pattern that means less difference in radon concentration between the six dormitories. According to the Requirements for Indoor radon and its Daughters Control (GB-T 16146-2015), the annual mean value of equilibrium equivalent radon concentration in the built houses shall not exceed $200 \mathrm{~Bq} / \mathrm{m}^{3}$. From Table 1, it can be generally suggested that the radon concentration in each dormitory does not exceed the limit and is suitable for living.

\subsection{Level and Analysis of Absorbed Dose Rate of Indoor Air}

From the No. 1 building to the No.6 building, there are 342 measuring points for the absorbed dose rate. There are 288 points on both sides of the dormitory, with the maximum and minimum values of 10.9 and 13.6 respectively. The monitoring situation of absorbed dose rate on both sides of the dormitory is shown in Table 2. There are 54 measuring points in the dormitory administrator's office, with the maximum and minimum values of 13.1 and 11.2. The measurements are shown in Table 3. 
Table 1. Data of radon concentration in dormitory.

\begin{tabular}{ccccc}
\hline No. & Sample Size & Concentration Range $\left(\mathrm{Bq} / \mathrm{m}^{3}\right)$ & AVG $\left(\mathrm{Bq} / \mathrm{m}^{3}\right)$ & $\mathrm{SD}$ \\
\hline 1 & 12 & $13.6-34.6$ & 21.33 & 5.63 \\
2 & 12 & $11.3-28.3$ & 18.7 & 5.24 \\
3 & 12 & $11.3-29.2$ & 20.51 & 5.71 \\
4 & 12 & $15.9-29.8$ & 22.03 & 4.58 \\
5 & 12 & $15.1-31.4$ & 22.89 & 6.45 \\
6 & 12 & $15.1-27.5$ & 19.77 & 4.19 \\
\hline
\end{tabular}

Table 2. Data of absorbed dose rate on both sides of dormitory.

\begin{tabular}{ccccc}
\hline No. & Sample Size & Range $\left(\times 10^{-8} \mathrm{~Gy} / \mathrm{h}\right)$ & AVG $\left(\times 10^{-8} \mathrm{~Gy} / \mathrm{h}\right)$ & $\mathrm{SD}$ \\
\hline 1 & 48 & $11.4-13.4$ & 12.36 & 0.31 \\
2 & 48 & $11.2-12.6$ & 12 & 0.34 \\
3 & 48 & $11.4-12.9$ & 12.24 & 0.35 \\
4 & 48 & $11.5-13.5$ & 12.43 & 0.34 \\
5 & 48 & $11.9-13.6$ & 12.48 & 0.35 \\
6 & 48 & $10.9-13.6$ & 12.76 & 0.61 \\
\hline
\end{tabular}

Table 3. Data of intermediate absorbed dose rate in dormitory.

\begin{tabular}{ccccc}
\hline No. & Sample Size & Range & AVG & SD \\
\hline 1 & 9 & $11.5-12.6$ & 12.02 & 0.39 \\
2 & 9 & $11.2-12.5$ & 12.13 & 0.38 \\
3 & 9 & $11.7-12.6$ & 12.29 & 0.26 \\
4 & 9 & $11.7-12.8$ & 12.38 & 0.3 \\
5 & 9 & $11.7-12.6$ & 12.11 & 0.32 \\
6 & 9 & $11.8-13.1$ & 12.43 & 0.44 \\
\hline
\end{tabular}

From the measured data, the absorbed dose rate of each building does not change significantly with the rise of the floors, so the absorbed dose rate has little relationship with the height of the floors. The measurement data of all six buildings fluctuate between 11 and 14, and there is no significant difference in the absorbed dose rate of each building.

\subsection{Estimation and Evaluation of Effective Dose from $\gamma$ and Radon and Their Daughters}

\subsubsection{Estimation of External Dose}

Calculate the effective dose of indoor radiation for students with Formula 1. When calculating the annual effective dose rate, the environmental residence time, in Formula 1, shall be multiplied by 0.8 (indoor by 0.8 , outdoor by 0.2 ) for the whole year for a total of 8760 hours, equals to 7008 . The annual effective dose of students caused by indoor radiation in each building is calculated ac- 
cording to Formula 2, which is listed in Table 4. The annual effective dose of dorm-aunts and teachers caused by indoor radiation in the middle of each building is listed in Table 5 .

It can be seen from Table 4 that the annual effective dose caused by indoor radiation in No.6 building is the highest, while the effective dose in Building 2 is the lowest, with a difference of $0.000037 \mathrm{~Sv}$, among the six dormitory buildings. In general, the annual effective dose rates for students in the six buildings did not differ significantly.

Table 5 shows the annual effective dose rate of dorm-aunts and teachers. The data shows that the annual effective dose of auntie in No.6 building is the largest, while that in No.1 building is the smallest, with a difference of 0.000021 . There is no obvious difference between the annual effective dose received by the residential students, the dormitory administrator and the teacher in the table. Compared to the annual effective dose limit specified in the Basic Standards for Protection against Ionizing Radiation and Safety of Radiation Sources (GB18871-2002), the annual effective dose caused by radiation of the dormitory did not exceed the limit, and is suitable for living.

\subsubsection{Estimation of Internal Dose}

In the process of calculating the annual effective dose caused by radon and its daughters in each dormitory, the average value of radon concentration in each building in Table 1 is used to calculate the annual effective dose rate. And the annual effective dose received by residents in each building is calculated and shown in Table 6, according to Table 1 and Formula 1.

The data show that the maximum annual effective dose is received in No.5; building and the minimum dose is received in No.2 building; though the same building-material of those six residential building, as it is mentioned in the preface that radon concentration is not only related to the building materials, but also related to indoor ventilation. While the ventilation effect is stumble inside the dormitories, and most of the dormitories have difficult in fluid ventilation. Thus, the reason for the dose of No.5 building is higher is that most of the pictures are painted with watercolor paint in the corridor there, which may be one of the reasons.

Table 4. Annual effective dose for students.

\begin{tabular}{cc}
\hline No. & AED (Sv) \\
\hline 1 & 0.000610 \\
2 & 0.000589 \\
4 & 0.0006 \\
5 & 0.000610 \\
6 & 0.000612 \\
\end{tabular}


Table 5. Annual effective dose for dorm-aunts and teachers.

\begin{tabular}{cc}
\hline No. & ED (Sv) \\
\hline 1 & 0.000589 \\
2 & 0.000595 \\
3 & 0.000602 \\
4 & 0.000607 \\
5 & 0.000594 \\
6 & 0.00061
\end{tabular}

Table 6. Annual effective dose of radon and its daughter.

\begin{tabular}{cc}
\hline No. & IAED \\
\hline 1 & 0.00209 \\
2 & 0.00183 \\
3 & 0.00201 \\
4 & 0.00216 \\
5 & 0.00225 \\
6 & 0.00194 \\
\hline
\end{tabular}

\section{Conclusions}

1) The data show that the absorbed dose rate of the six dormitories fluctuated between $11 \times 10^{-8} \mathrm{~Gy} / \mathrm{h}-14 \times 10^{-8} \mathrm{~Gy} / \mathrm{h}$ when the absorbed dose rate is measured. The average absorbed dose rate of each dormitory is so close that there is no significant difference between the data.

2) The radon concentration measured in the six dormitories fluctuated between $11.3 \mathrm{~Bq} / \mathrm{m}^{3}-34.6 \mathrm{~Bq} / \mathrm{m}^{3}$. The average difference of radon concentration in each dormitory is not significant, and the measured values are all in accordance with the standards and living standards.

3) The annual effective dose of radiation in dormitory, calculated by Formula 1 , is lower than the national standard.

4) The radon concentration value is converted into the annual effective dose of residents, calculated by Formula 2, which is far lower than the standard, and the dormitory is suitable for living.

\section{Conflicts of Interest}

The authors declare no conflicts of interest regarding the publication of this paper.

\section{References}

[1] Yang, Q.Y., Gu, M.Y., Zhang, X.F., et al. (1991) All Kinds of Buildings in Our Country Interior Gamma Radiation Dose Rate and Its Residents to Estimate of Annual Effective Dose Equivalent. Journal of Chongqing Environmental Science, No. 3, 26-28. 
[2] Liu, C.Y., Chen, L. and Han, W.S. (2008) The Investigation and Analysis of Radon Concentration in Harbin University Students' Dormitory. China Radiation Health, No. 1, 62-63.

[3] Li, J.Z. and Mei, Z.M. (1995) Radioactive Hazard in Indoor Environment.

[4] Lin, D., Zhao, S.M., Chen, W.Y., et al. (2001) Fuzhou Part of the Housing Indoor Radioactivity Level Test Results Analysis. Journal of the Channel, No. 2, 52.

[5] Yang, Y.W., Zhang, J.Z., Zhao, Z.H., et al. (2004) Indoor Radioactivity Level and Evaluation in Hebei Province. China Radiation Health, No. 4, 259.

[6] Wang, J. (2004) Present Status of Indoor Radon Control Standards and Discussion. China Radiation Health, No. 1, 73-74.

[7] Su, Y., Ye, X.B., Li, F., et al. (2006) Some after 31 Families Decorate Indoor Radioactivity Level Survey. Journal of Preventive Medicine in the People's Liberation Army, No. 5, 343-344.

[8] Zhao, H.G. (2007) Outside the Radiation Accident Exposure Dose Quick Estimate. Suzhou University, Suzhou.

[9] Cheng, Y.X. (2008) The Harm of Radon and Its Daughter and Control in the Environment. Modern Geology, No. 5, 857-868.

[10] Wang, K., Hong, D., Yao, H.M., et al. (2009) Neijiang, Residential Indoor Radioactivity Research. Journal of a District of Neijiang Normal College Journal, No. S2, 230-231.

[11] Xiao, Y.J., Xiao, D.T. and Tang, L. (2011) Hunan Hengyang Xiangtan Regions Indoor Natural Radioactive Level Investigation. Journal of Radiation Protection, No. $5,317-322$.

[12] Xu, L.P., Ge, L.Q., Ceng, B., et al. (2012) Chengdu Area Survey. Journal of Indoor Radon Concentration of Radiation Protection, 32, 177-180.

[13] Lin, Y., Xu, M.F. and Hui, X.Y. (2013) Nanning the Radiation Level Is a Newly Built Highrise Residential Building Measurement Analysis. Journal of Popular Science and Technology, No. 7, 67-68.

[14] Ma, J.Y., Li, D.Z., Jin, H., et al. (2014) For the Air Radon Level Investigation and Evaluation. China Radiation Health, 23, 392-396.

[15] Xu, L.P., Deng, X.Q., Ge, L.Q., et al. (2016) Investigation on Indoor Radon Concentration and Dose Rate in Urban and Rural Areas of Chengdu City. Radiation Protection, 36, 224-231.

[16] Ma, N., Cheng, Q.J., Wu, W.W., et al. (2015) Suggestions on Occupational Exposure and Protection for Nuclear Medical Practitioners in China. China Occupational Medicine, 45, 119-122.

[17] Kobayashi, T. (2006) Indoor-Atmospheric Radon-Related Radioactivity Affected by a Change of Ventilation Strategy. Fukushima Journal of Medical Science, 52, 59-64. https://doi.org/10.5387/fms.52.59

[18] Calin, M., Calin, M., Simionca, G., et al. (2012) Indoor Radon Levels and Natural Radioactivity in Turda Salt Mine, Romania. Journal of Radioanalytical \& Nuclear Chemistry, 292, 193-201. https://doi.org/10.1007/s10967-011-1394-2

[19] Todorović, N., et al. (2014) Radioactivity in the Indoor Building Environment in Serbia. Radiation Protection Dosimetry, 158, 208-215.

https://doi.org/10.1093/rpd/nct210 